Parasitology

\title{
Identification of Leishmania (Viannia) species and clinical isolates of Leishmania (Leishmania) amazonensis from Brazil using PCR-RFLP of the heat-shock protein 70 gene reveals some unexpected observations
}

\author{
Caroline R. Espada a , Paola A. Ortiz a, Jeffrey J. Shaw ${ }^{\text {a }}$, Aldina M.P. Barral ${ }^{\text {b }}$, Jackson M.L. Costa ${ }^{\text {b }}$, \\ Silvia R.B. Uliana ${ }^{\text {a }}$, Adriano C. Coelho ${ }^{\mathrm{a}, *, 1}$ \\ a Departamento de Parasitologia, Instituto de Ciências Biomédicas, Universidade de São Paulo, São Paulo, 05508-900, SP, Brazil \\ b Instituto Gonçalo Moniz, Fundação Oswaldo Cruz (FIOCRUZ), Salvador, 40296-710, BA, Brazil
}

\section{A R T I C L E I N F O}

\section{Article history:}

Received 9 October 2017

Received in revised form 8 February 2018

Accepted 7 March 2018

Available online 12 March 2018

\section{Keywords:}

Leishmania (Leishmania) amazonensis

Leishmania (Viannia) species

hsp70

PCR-RFLP

molecular diagnosis

\begin{abstract}
A B S T R A C T
Hsp70 is a cytoplasmic heat-shock protein, encoded by a multicopy tandemly repeated gene that has recently been gaining popularity as a valuable marker for typing Leishmania species. In this study, we used a previously described hsp70 PCR-RFLP method for identifying Brazilian Leishmania isolates. We identified two distinct L. (L.) amazonensis hsp70 alleles that resulted in two different RFLP patterns. Also, we found RFLP polymorphisms amongst $L$. (Viannia) naiffi strains. The profiles of both $L$. (V.) shawi and $L$. (V.) lindenbergi were very similar to those of other $L$. (Viannia) species. The observations described herein reflect the polymorphism found within species of Leishmania and indicate that results from this hsp70 PCR-RFLP method should be used with caution when typing isolates from clinical cases of leishmaniasis and Leishmania species from Brazil.
\end{abstract}

(C) 2018 Elsevier Inc. All rights reserved.

\section{Introduction}

Leishmaniasis is a complex of vector borne diseases caused by protozoan parasites belonging to subfamily Leishmaniinae (Espinosa et al., 2016). The disease is endemic in 98 countries located in tropical and subtropical areas and recent data indicate that 1.2 million cases of visceral and cutaneous leishmaniasis occur worldwide every year (Alvar et al., 2012). Some 24-different named species of the subfamily (Espinosa et al., 2016), this includes one that does not belong to the genus Leishmania, can cause diseases with different clinical symptoms that depend on the species involved as well as on the host genetics (Arevalo et al., 2007; Murray et al., 2005). In Brazil, the principal etiological agents of cutaneous leishmaniasis are L. (Viannia) braziliensis and $L$. (Leishmania) amazonensis, although other species from the

Abbreviations: bp, base pair; hsp70, heat-shock protein 70; MLEE, multilocus enzyme electrophoresis; PCR, polymerase chain reaction; RFLP, restriction fragment length polymorphism; SNP, single-nucleotide polymorphism.

* Corresponding author. Tel.:+55-19-35210028.

E-mail address: accoelho@unicamp.br (A.C. Coelho).

1 Present address: Departamento de Biologia Animal, Instituto de Biologia, Universidade Estadual de Campinas, Campinas, 13083-862, SP, Brazil. subgenus $L$. (Viannia) such as $L$. (V.) guyanensis, $L$. (V) naiffi, $L$. (V) lainsoni, L. (V) shawi and $L$. (V) lindenbergi also cause the disease. Additionally, $L$. $(V)$ utingensis is also found in Brazil, but so far it has not been recorded in humans (Braga et al., 2003). The identification and classification of these species was originally based on multilocus enzyme electrophoresis (MLEE) (Cupolillo et al., 1994).

Several molecular assays for identifying Leishmania species have been developed based on either kinetoplast or genomic DNA. Various targets have been used such as the ribosomal DNA internal transcribed spacer (Cupolillo et al., 1995; Schonian et al., 2003), the miniexon (Marfurt et al., 2003), cytochrome B (Asato et al., 2009), and heatshock protein 70 ( $h s p 70$ ) (Fraga et al., 2012) encoding genes.

What drew attention to hsp70 was that its identifications matched almost perfectly those of MLEE, which is still considered as the gold standard for Leishmania species identification (Cupolillo et al., 1994; Rioux et al., 1990). This cytoplasmic heat-shock protein, is encoded by a multicopy tandemly repeated gene in Leishmania spp., present in 5 to 10 copies in the parasite genome (Folgueira et al., 2007; Ramirez et al., 2011). Garcia et al. (2004) developed a PCR assay employing RFLP with primers designed from the conserved common hsp70 sequences of $L$. (V.) braziliensis and $L$. (L.) mexicana. In subsequent studies this method differentiated 15 Leishmania species belonging to the two subgenera including the principal species found in Brazil's 
Table 1

Leishmania strains and isolates used in this study.

\begin{tabular}{|c|c|c|c|}
\hline International code & Species & Clinical form and origin (Brazilian State) & Reference \\
\hline MHOM/BR/73/M2269 & L. (L.) amazonensis & CL (Pará) & (Miles et al., 1980) \\
\hline MPRO/BR/72/M1841-LV79 & L. (L.) amazonensis & $\mathrm{LCL}$ & (Chance et al., 1974) \\
\hline IFLA/BR/67/PH8 & L. (L.) amazonensis & - (Pará) & (Miles et al., 1980) \\
\hline MHOM/BR/2008/2506 & L. (L.) amazonensis & DCL (Piauí) & (Coelho et al., 2014) \\
\hline MHOM/BR/87/BA109 & L. (L.) amazonensis & VL (Bahia) & (de Oliveira et al., 2007) \\
\hline MHOM/BR/89/BA199 & L. (L.) amazonensis & DCL (Bahia) & (de Oliveira et al., 2007) \\
\hline MHOM/BR/89/BA276 & L. (L.) amazonensis & DCL (Bahia) & (de Oliveira et al., 2007) \\
\hline MHOM/BR/75/M2903 & L. (V.) braziliensis & CL (Pará) & (Laison et al., 1973) \\
\hline MHOM/BR/75/M4147 & L. (V.) guyanensis & CL (Pará) & (Lainson et al., 1979) \\
\hline MHOM/BR/2002/ACVJ & L. (V.) guyanensis & $\mathrm{CL}$ (Amazonas) & (This study) \\
\hline MHOM/BR/1981/M6426 & L. (V.) lainsoni & CL (Pará) & (Silveira et al., 1987) \\
\hline MHOM/BR/96/M15732 & L. (V.) lindenbergi & CL (Pará) & (Silveira et al., 2002) \\
\hline IAYR/BR/86/EO337 & L. (V.) naiffi & (Bahia) & (This study) \\
\hline MDAS/BR/79/M5533 & L. (V.) naiffi & (Pará) & (Lainson and Shaw, 1989) \\
\hline MCEB/BR/84/M8408 & L. (V.) shawi & (Pará) & (da Silva et al., 2010) \\
\hline ITUB/BR/77/M4964 & L. (V.) utingensis ${ }^{\mathrm{a}}$ & - & (Braga et al., 2003) \\
\hline
\end{tabular}

CL, cutaneous leishmaniasis; DCL, diffuse cutaneous leishmaniasis; LCL, localized cutaneous leishmaniasis.

a Isolated from Lutzomyia tuberculata and have not been found in humans (Braga et al., 2003).

endemic regions (da Silva et al., 2010; Montalvo et al., 2012; Van der Auwera and Dujardin, 2015). However, in one analysis (da Silva et al., 2010), using the sequences of the PCR products, a strain of $L$. (V.) braziliensis from the Mato Grosso State grouped with a low bootstrap value with isolates of $L$. (V.) shawi.

In our laboratory we routinely use the $h s p 70$ PCR-F-RFLP described by Montalvo et al. (2012) to identify isolates from patients. In this paper, we report polymorphisms of the $h s p 70$ genes in isolates of $L$. (L.) amazonensis and in strains of the subgenus L. (Viannia) that should be taken into consideration when identifying or typing these parasites.

\section{Material and methods}

\subsection{Reference strains and clinical isolates}

Leishmania promastigotes were grown in medium 199 (SigmaAldrich) supplemented with 10\% heat-inactivated fetal calf serum, $0.25 \%$ hemin, $12 \mathrm{mM} \mathrm{NaHCO}, 50 \mathrm{U} / \mathrm{mL}$ penicillin and $50 \mu \mathrm{g} / \mathrm{mL}$ streptomycin at $25{ }^{\circ} \mathrm{C}$. For the cultivation of Leishmania (Viannia) spp., $2 \%$ sterile human urine was added to the medium. The reference strains and isolates used are described in Table 1. Apart from isolate MHOM/BR/2002/ACVJ,

Table 2

In silico analysis of the 1,286 bp hsp70 amplified product in Leishmania spp. Size of products generated by digestion with selected restriction enzymes.

\begin{tabular}{|c|c|c|c|c|}
\hline $\begin{array}{l}\text { Leishmania sp./restriction } \\
\text { enzyme }\end{array}$ & Eco RII & Hae III & Mbo I & Sdu I \\
\hline $\begin{array}{l}\text { L. (L.) amazonensis M2269 } \\
\quad \text { allele } 1^{\mathrm{a}}\end{array}$ & $441,320,210,123,117,75$ & $\underline{\mathbf{3 3 8}}, 307, \underline{\mathbf{2 4 6}}, 233,62,47,40,13$ & $390,258,177,141,114,81,42,38,21,18,6$ & $525,321,273,111,56$ \\
\hline $\begin{array}{l}\text { L. (L.) amazonensis M2269 } \\
\text { allele } 2^{\text {a }}\end{array}$ & $441,320,210,123,117,75$ & $\underline{\mathbf{5 8 4}}, 307,233,62,47,40,13$ & $390,258,177,141,114,81,42,38,21,18,6$ & $525,321,273,111,56$ \\
\hline L. (V.) lainsoni CUM71 ${ }^{\mathrm{b}}$ & $333,321, \mathbf{3 1 5}, 120,117, \mathbf{5 4}, \mathbf{2 1}, 5$ & $338, \mathbf{3 3 3}, 307, \mathbf{1 2 0}, 59, \mathbf{5 4}, 41,21,13$ & $390,213,141,123, \mathbf{1 1 4}, 114, \mathbf{6 3}, \mathbf{4 5}, 38,21,18,6$ & $\mathbf{5 2 5}, 321,273,111,56$ \\
\hline L. (V.) braziliensis M2903 c & $333,321, \mathbf{1 8 6}, \mathbf{1 3 4}, 120,117, \mathbf{5 4}, 21$ & $338,307,286, \mathbf{1 3 4}, 59,47,41, \mathbf{4 0}, 21,13$ & $390,213, \mathbf{1 7 7}, \mathbf{1 5 9}, 141,123,38,21,18,6$ & 411, $321,273,114,111,56$ \\
\hline L. (V.) peruviana $\mathrm{LH} 2864^{\mathrm{d}}$ & $333,321, \mathbf{1 8 6}, \mathbf{1 3 4}, 120,117, \mathbf{5 4}, 21$ & $338,307,286, \mathbf{1 3 4}, 59,47,41, \mathbf{4 0}, 21,13$ & $390,213, \mathbf{1 7 7}, \mathbf{1 5 9}, 141,123,38,21,18,6$ & $\mathbf{4 1 1}, 321,273,114,111,56$ \\
\hline L. (V.) naiffi $\mathrm{M} 5210^{\mathrm{e}}$ & $333,321, \mathbf{1 8 6}, \mathbf{1 3 4}, 120,117, \mathbf{5 4}, 21$ & $338,307,286, \mathbf{1 3 4}, 59,47,41, \mathbf{4 0}, 21,13$ & $390,213, \mathbf{1 7 7}, 141,123, \mathbf{1 1 4}, \mathbf{4 5}, 38,21,18,6$ & $\mathbf{5 2 5}, 321,273,111,56$ \\
\hline L. (V.) naiffi $\mathrm{M} 5533^{\mathrm{f}}$ & $333,321, \mathbf{1 8 6}, \mathbf{1 3 4}, 120,117, \mathbf{5 4}, 21$ & $338,307,286, \mathbf{1 3 4}, 59,47,41, \mathbf{4 0}, 21,13$ & $390,213, \mathbf{1 7 7}, 141,123, \mathbf{1 1 4}, \mathbf{4 5}, 38,21,18,6$ & $\mathbf{5 2 5}, 321,273,111,56$ \\
\hline L. (V.) naiff EO337 ${ }^{\mathrm{g}}$ & $333,321, \mathbf{1 8 6}, \mathbf{1 3 4}, 120,117, \mathbf{5 4}, 21$ & $338,307,286, \mathbf{8 0}, 59, \mathbf{5 4}, 47,41, \mathbf{4 0}, 21,13$ & $390,213, \mathbf{1 7 7}, 141,123, \mathbf{1 1 4}, \mathbf{4 5}, 38,21,18,6$ & $\mathbf{5 2 5}, 321,273,111,56$ \\
\hline L. (V.) panamensis M4039 ${ }^{\mathrm{h}}$ & $333,321, \mathbf{3 2 0}, 120,117,75$ & $338,307,286,174,59,47,41,21,13$ & $390,213, \mathbf{1 5 9}, 141,123, \mathbf{1 1 4}, \mathbf{6 3}, 38,21,18,6$ & $\mathbf{4 1 1}, 321,273,114,111,56$ \\
\hline L. (V.) guyanensis $\mathrm{M} 4147^{\mathrm{i}}$ & $333,321, \mathbf{3 2 0}, 120,117,75$ & $338,307,286, \mathbf{1 7 4}, 59,47,41,21,13$ & $390,213, \mathbf{1 5 9}, 141,123, \mathbf{1 1 4}, \mathbf{6 3}, 38,21,18,6$ & $\mathbf{4 1 1}, 321,273,114,111,56$ \\
\hline L. (V.) guyanensis ACVJ ${ }^{\mathrm{j}}$ & $333,321, \mathbf{3 2 0}, 120,117,75$ & $338,307,286,174,59,47,41,21,13$ & $390,213, \mathbf{1 5 9}, 141,123, \mathbf{1 1 4}, \mathbf{6 3}, 38,21,18,6$ & $\mathbf{4 1 1}, 321,273,114,111,56$ \\
\hline L. (V.) shawi M8408 ${ }^{\mathrm{k}}$ & $333,321, \mathbf{3 2 0}, 120,117,75$ & $338,307,286, \mathbf{1 2 0}, 59, \mathbf{5 4}, 47,41,21,13$ & $390,213, \mathbf{1 5 9}, 141,123, \mathbf{1 1 4}, \mathbf{6 3}, 38,21,18,6$ & 411, 321, 273, 114, 111, 56 \\
\hline L. (V.) lindenbergi $\mathrm{M} 15732^{1}$ & $333,321, \mathbf{3 2 0}, 120,117, \mathbf{5 4}, 21$ & $338,307,286,174,59,47,41,21,13$ & $390,213, \mathbf{1 7 7}, 141,123, \mathbf{1 1 4}, \mathbf{4 5}, 38,21,18,6$ & $\mathbf{5 2 5}, 321,273,111,56$ \\
\hline L. (V.) utingensis M4964 ${ }^{\mathrm{m}}$ & $333,321, \mathbf{1 8 6}, \mathbf{1 3 4}, 120,117, \mathbf{5 4}, 21$ & $338,307,286, \mathbf{1 3 4}, 59,47,41, \mathbf{4 0}, 21,13$ & $390,213, \mathbf{1 7 7}, \mathbf{1 5 9}, 141,123,38,21,18,6$ & $\mathbf{4 1 1}, 384,321, \mathbf{1 1 4}, 56$ \\
\hline
\end{tabular}

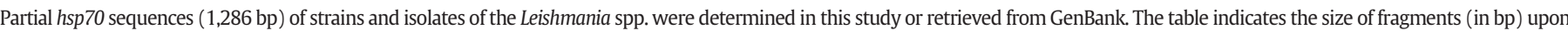

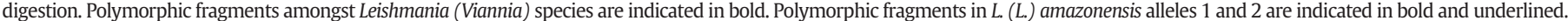

a GenBank accession number: MG029123

b GenBank accession number: FN395047

c GenBank accession number: XM 001566275

d GenBank accession number: FN395044

e GenBank accession number: FN395056

f GenBank accession number: FR872767

g GenBank accession number: MG029126

h GenBank accession number: FN395055

i GenBank accession number: EU599093

j GenBank accession number: MG029128

k GenBank accession number: MG029127

${ }^{1}$ GenBank accession number: MG029124

m GenBank accession number: MG029125 
all parasites used here were also typed by isoenzymes or molecular methods (references in Table 1).

\subsection{PCR amplification of $h s p 70$}

Genomic DNAs of Leishmania parasites were purified using DNAzol according to the manufacturer's instructions and quantified by spectrophotometry in a microplate reader (POLARstar Omega, BMG Labtech, Ortenberg, Germany). For each PCR reaction, $100 \mathrm{ng}$ of DNA was used and PCRs were performed according to Montalvo et al. (2012). The primers used were F25 (5'-GGACGCCGGCACGATTKCT-3') and R1310 (5'- CCTGGTTGTTGTTCAGCCACTC-3'), which amplify the hsp70 PCR-F DNA fragment of $1,286 \mathrm{bp}$. The PCR amplifications were performed in a final volume of $50 \mu \mathrm{L}$ containing $0.2 \mu \mathrm{M}$ of each primer, $200 \mu \mathrm{M}$ dNTPs, $1.6 \mathrm{mM} \mathrm{MgCl}_{2}$ and $2.5 \mathrm{U}$ Taq DNA polymerase (Sinapse Biotecnologia, São Paulo, Brazil) using the following amplification cycle: $94^{\circ} \mathrm{C}$ for $5 \mathrm{~min}$ followed by 30 cycles of $94^{\circ} \mathrm{C}$ for $40 \mathrm{sec}, 60^{\circ} \mathrm{C}$ for $1 \mathrm{~min}$ and $72^{\circ} \mathrm{C}$ for $2 \mathrm{~min}$ and a final extension at $72^{\circ} \mathrm{C}$ for $10 \mathrm{~min}$ (Montalvo et al., 2012). The amplified products were analyzed by electrophoresis in $2 \%$ agarose gels stained with ethidium bromide.

\subsection{PCR-RFLPs analysis}

PCR products were digested with Hae III (New England Biolabs) after DNA quantification in agarose gel electrophoresis. Digestion products were separated in $2 \%$ or $3 \%$ agarose gels stained with ethidium bromide. The GeneRuler 100 bp DNA ladder (Life Technologies) was used as molecular weight marker.

\subsection{DNA sequencing}

The amplified products were purified from agarose gels using the GenElute Gel Extraction kit (Sigma-Aldrich, St. Louis, USA) and cloned in pGEM-T easy (Promega Corporation, Madison, USA). The nucleotide sequence of several independent positive clones containing the PCR-F fragment was determined in an automated DNA sequencer (ABI PRISM Big Dye Terminator Cycle Sequencing) using the Big Dye Terminator v3.1 Cycle Sequencing kit (Life Technologies). Primers used for sequencing were M13 primers, F25 and R1310. Consensus sequences were generated from at least three forward and three reverse sequences. Nucleotide sequence analyses were performed using Lasergene Software (DNASTAR) and Clone Manager 9.0 Software. Sequences determined in this study are listed in Table 2 and are available in the GenBank.

\subsection{Data analysis and phylogenetic inferences using hsp70 sequences}

The partial nucleotide sequences of 1,286 bp of the $h s p 70$ gene were aligned using ClustalW and then edited using the program GeneDoc 2.6 (Nicholas et al., 1997). Phylogenies were inferred using the maximum likelihood (ML) and maximum parsimony (MP) analyses. The parsimony and their respective bootstrap analyses were carried out using PAUP version 4.0b10 (Swofford, 2002) with 100 replicates of random addition sequences followed by branch swapping (RAS-TBR). The ML analyses were performed using RAxML version 2.2.3 (Stamatakis, 2006), with tree searches performed with GTR model with gammadistributed rate variation across sites and proportion of invariable sites (GTRGAMMA model) and nodal supports were estimated with 100 bootstrap replicates in RAxML using GTRGAMMA and maximum parsimony starting trees.

\section{Results}

\subsection{The L. (L.) amazonensis hsp70 gene is polymorphic}

The PCR-F-RFLP protocol described by (Montalvo et al., 2012) has been recently adopted in our laboratory as a tool for species identification of Leishmania clinical isolates. Amongst isolates and reference strains of $L$. ( $L$.) amazonensis, specific amplification of the expected hsp70 fragment of approximately $1.3 \mathrm{~kb}$ was observed (Fig. 1A). However, the digestion of the fragment obtained from the $L$. ( $L$.) amazonensis M2269 reference strain with the restriction enzyme Hae III generated an unexpected 580 bp band (Fig. 1B) that had not been reported previously in isolates of $L$. (L.) amazonensis and $L$. ( $L$.) mexicana (Fraga et al., 2012; Montalvo et al., 2012). Interestingly, this approximately 580 bp fragment was also observed in Hae III digested products obtained from clinical isolates 2506 and BA-199, but was absent in other clinical isolates of the same species (BA-109 and BA-276) and was not observed in the reference strains LV79 and PH8 (Fig. 1B).

To characterize this unexpected digestion pattern, the $1.3 \mathrm{~kb}$ M2269 amplified fragment was cloned in the pGEM-T easy vector and 8 independent positive clones were screened by digestion with Hae III. Two different patterns of amplified fragments were found: containing or not the fragment of $580 \mathrm{bp}$ ( 3 and 5 clones respectively) (Table 2). Representative clones of the two distinct patterns had their nucleotide sequence determined revealing the absence of a Hae III site due a synonymous polymorphism at position $894(\mathrm{GCC} / \mathrm{GCT} \rightarrow \mathrm{A} / \mathrm{A})$ of the hsp70 open reading frame in one of the alleles. In addition, another SNP (a non-synonymous SNP) at position 578 (AAG/ATG $\rightarrow$ K/M) was also found in the second allele of this $L$. (L.) amazonensis strain. The

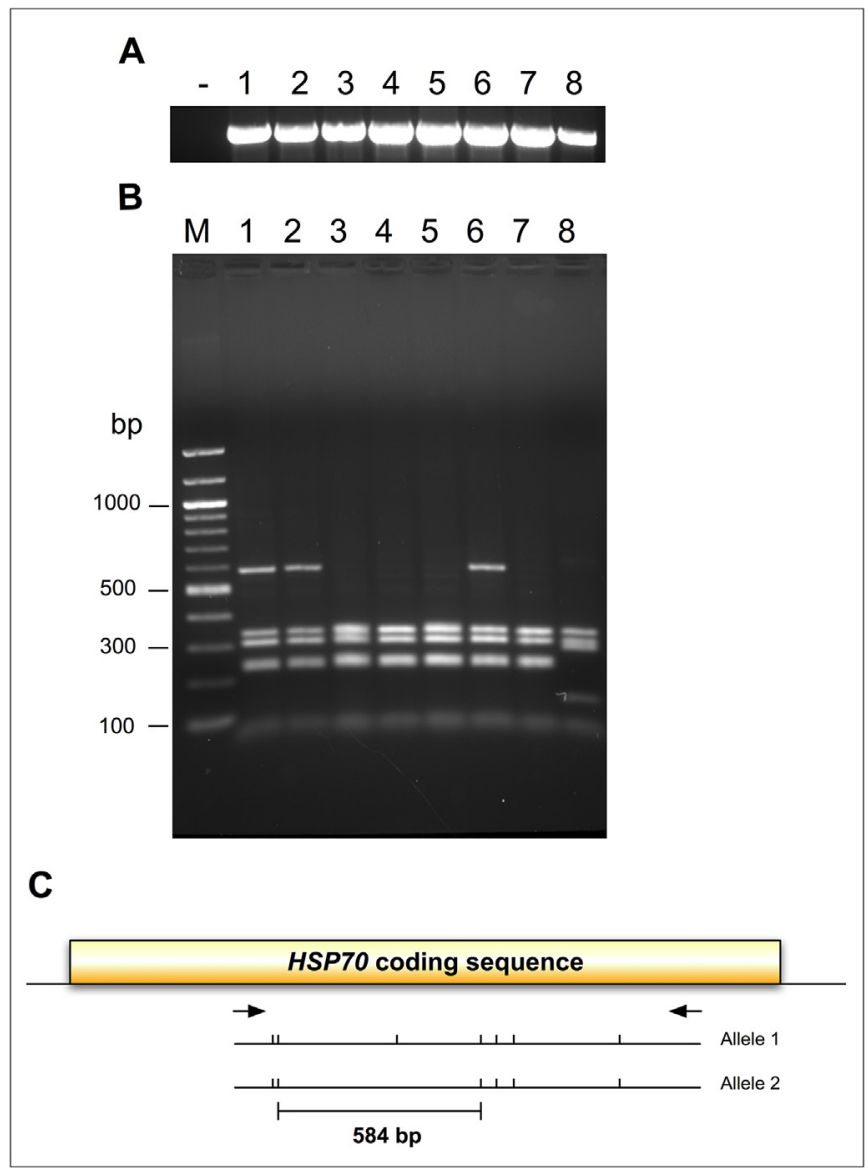

Fig. 1. Identification of two L. (L.) amazonensis hsp70 alleles (1 and 2 ) by PCR-RFLP. (A) hsp70 gene amplification (1,286 bp fragment) using the PCR-F protocol described by (Fraga et al., 2012). (B) Digestion of the amplified products shown in (A) with Hae III and size-separation in ethidium bromide stained $2 \%$ agarose gel. (-) Negative control; 1 - L. (L.) amazonensis M2269; 2- L. (L.) amazonensis 2506 isolate; 3 - L. (L.) amazonensis LV79; 4- L. (L.) amazonensis PH8; 5 - L. (L.) amazonensis BA109 isolate; 6 - L. (L.) amazonensis BA199 isolate; 7 - L. (L.) amazonensis BA276 isolate; 8 - L. (V.) braziliensis M2903. (C) Restriction map analysis of the two L. (L.) amazonensis (strain M2269) hsp70 alleles. The Hae III restriction sites and the $584 \mathrm{bp}$ fragment from allele 2 are indicated. 
Hae III restriction map for the two alleles is shown in Fig. 1C. In silico analysis of restriction patterns upon digestion with Eco RII, Mbo I and Sdu I, enzymes previously described as useful for $h s p 70$ PCR-RFLP typing (da Silva et al., 2010; Fraga et al., 2013; Montalvo et al., 2012), confirmed that both alleles have a conserved restriction profile for these three restriction enzymes (Table 2).

\subsection{Polymorphisms on L. (V.) naiffi and L. (V.) shawi hsp70 genes}

A variety of species of the $L$. (Viannia) subgenus has been implicated in tegumentary leishmaniasis in Brazil. Aiming to implement the $h s p 70$ PCR-F-RFLP followed by Hae III digestion as a routine to identify Leishmania species in our laboratory, we employed a panel of reference strains from the Viannia subgenus (Table 1). Apart from the most widespread species, the panel also included $L$. (V.) naiffi, $L$. (V.) shawi, $L$. (L.) lainsoni, $L$. (V.) lindenbergi, for which the $h s p 70$ gene had not been previously studied, and $L$. $(V$.) utingensis, which has not yet been found in humans. The RFLP profile obtained after Hae III digestion for $L$. (V.) braziliensis M2903 was, as expected, indistinguishable from $L$. (V.) naiffi M5553 (Fig. 2A). As some degree of heterogeneity amongst $L$. (V.) naiffi isolates was detected by Montalvo et al. (2012), we added to the analysis, together with the reference strain $L$. (V.) naiffi M5533, the isolate L. (V.) naiffi EO337 for a more accurate comparison. A different pattern of Hae III digestion was identified in the EO337 strain, previously typed as $L$. (V.) naiffi. This new restriction pattern was due to the presence of an additional Hae III restriction site located at the extremity of the amplified fragment (Fig. 2B) and confirmed a degree of intraspecies heterogeneity in $L$. (V.) naiffi. Nevertheless, in silico analyses indicated that these two strains of $L$. (V.) naiffi (M5533 and EO337) and also M5210 of this same species displayed the same restriction profile when digested with Eco RII, Mbo I or Sdu I (Table 2). L. (V.) lainsoni M6426 profile was unique amongst the species tested (Fig. 2A).

RFLP profiles for $L$. (V.) shawi, $L$. (V.) braziliensis M2903, L. (V.) naiffi 5533 and $L$. (V.) utingensis M4964 contain fragments in the region of 120-140 bp, of similar sizes, which can be distinguished only in highly stringent electrophoresis conditions (Fig. 2 and Table 2). The nucleotide sequence of $L$. (V.) shawi M8408 hsp70 PCR-F 1,286 bp fragment was determined. The sequence (Genbank no. MG029127) showed 99.8\% identity with the $L$. (V.) guyanensis M4147 strain homologous sequence, while $99.4 \%$ identity was found with $L$. (V.) braziliensis M2903 (data not shown). Therefore and as expected, sequence data can be used to rule out typing $L(V$.) shawi as $L$. (V.) braziliensis, in cases where the electrophoresis patterns cannot be relied upon.

In order to increase the panel of restriction enzymes that could be useful to discriminate these L. (Viannia) species and strains, we performed in silico analyses of the PCR-F 1,286 bp fragment using the following restriction enzymes: Eco RII, Mbo I, and Sdu I. Unlike Hae III, the restriction enzymes Eco RII and Mbo I were useful to discriminate L. (V.) shawi M8408 from L. (V.) braziliensis/L. (V.) peruviana, L. (V.) naiffi and $L$. (V.) utingensis (Table 2). On the other hand, Eco RII, Mbo I and Sdu I restriction patterns of $L$. (V.) guyanensis/L. (V.) panamensis and $L(V$.) shawi M8408 are identical (Table 2). Besides that, the PCR-F RFLP

A

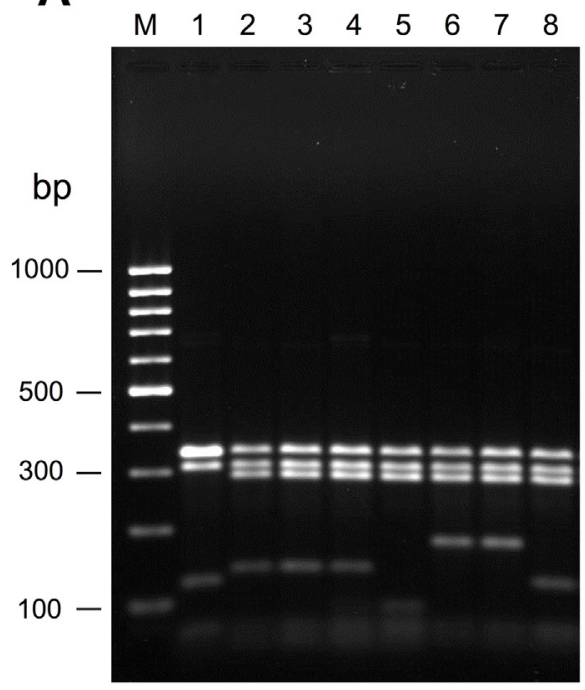

B

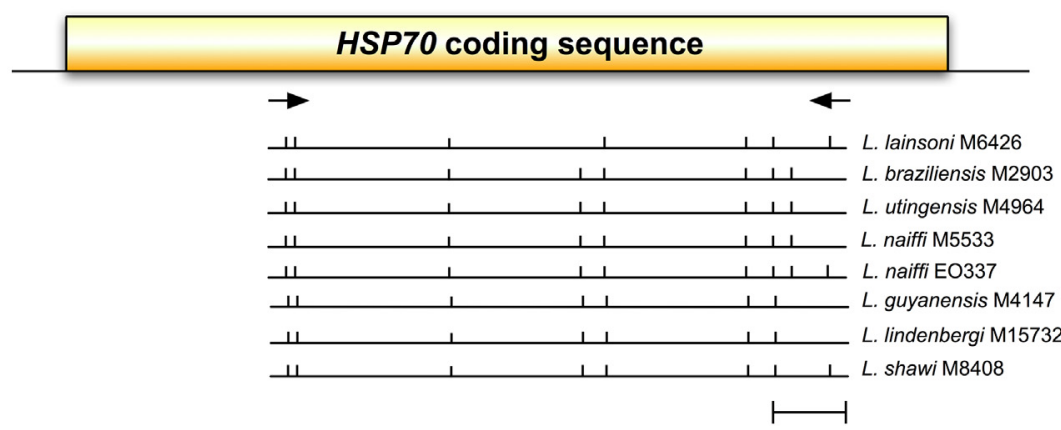

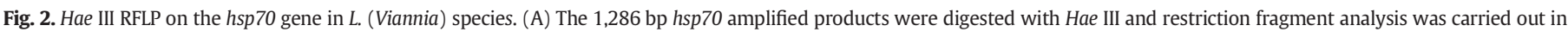

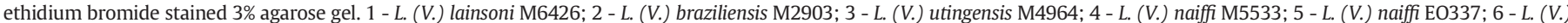

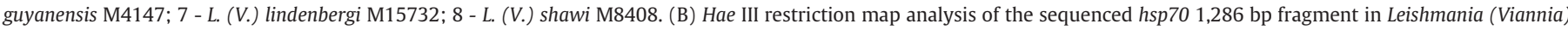

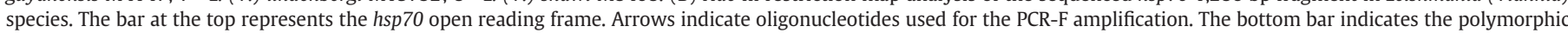
region in the amplified fragment. 
using $S d u$ I was shown to be useful to discriminate $L$. (V.) naiffi from L. (V.) guyanensis/L. (V.) panamensis, L. (V.) braziliensis/L. (V.) peruviana or L. (V.) shawi M8408 (Table 2).

\subsection{Analysis of L. (V.) lindenbergi and L. (V.) utingensis hsp70 gene}

We also characterized for the first time the partial hsp70 sequences of $L$. (V.) lindenbergi and added a new partial sequence for $L$. (V.) utingensis. At the time of writing, only a fragmentary annotation of this species $h s p 70$ gene was available. L. (V.) lindenbergi Hae III PCR-F-RFLP was indistinguishable from L. (V.) guyanensis/L. (V.) panamensis strains and different from $L$. (V.) shawi (Table 2). The sequence analyses indicated that PCR-F RFLPs of $L$. (V.) lindenbergi can only be discriminated from other L. (Viannia) species using Eco RII, since $M b o$ I and $S d u$ I produced the same restriction profile of $L$. (V.) naiffi (Table 2).

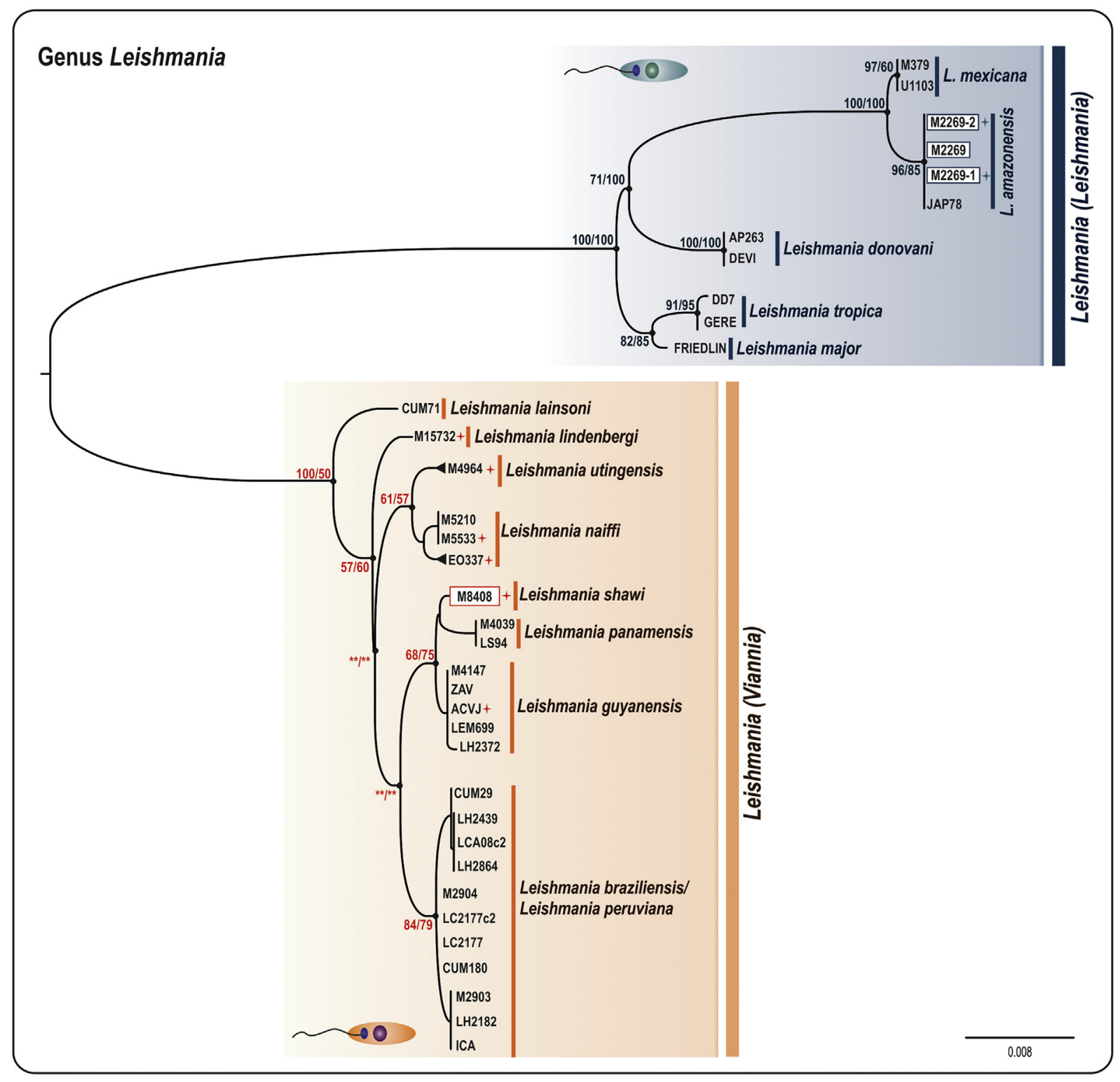

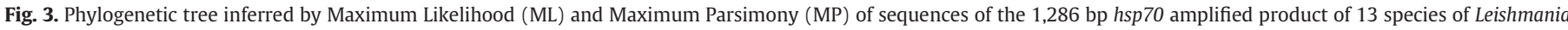

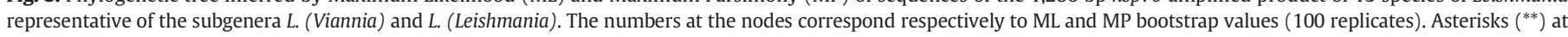

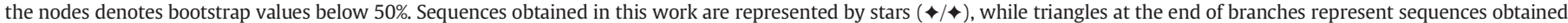

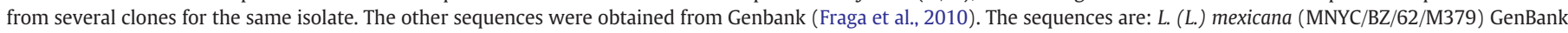

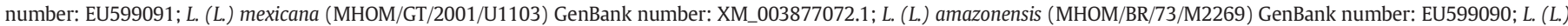

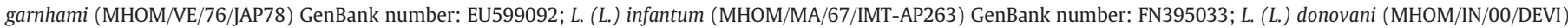

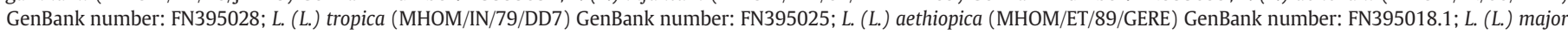

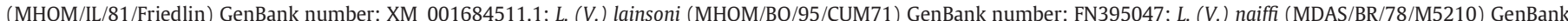

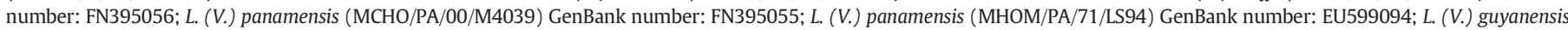

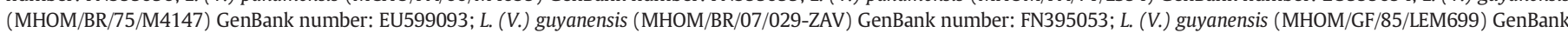

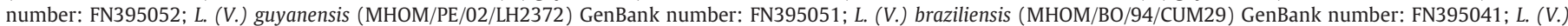

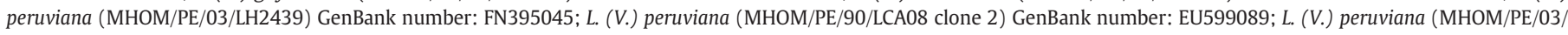

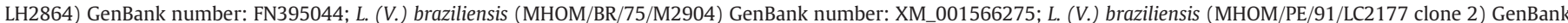

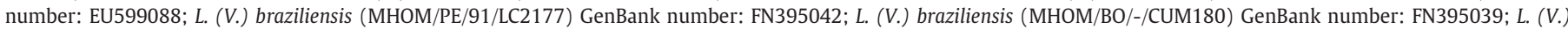

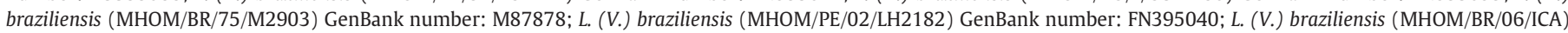
GenBank number: FN395043. 
Finally for $L$. (V.) utingensis, the PCR-F-RFLP of this species has the same restriction profile of $L$. (V.) braziliensis/L. (V.) peruviana for the 4 enzymes analyzed and so none of the enzymes are useful to discriminate it from other L. (Viannia) species (Fig. 2 and Table 2).

\subsection{Phylogenetic analyses}

The phylogenetic tree using the $h s p 70$ gene sequences of several Leishmania species indicated the presence of the main groups of the Leishmania genus (Fig. 3). As reported previously, we observed that $L$. $(V$.) guyanensis is placed in the same cluster of $L$. (V.) panamensis and $L$. (V.) shawi (Boite et al., 2012). Similarly, L. (V.) braziliensis and $L$. (V.) peruviana are also located in the same cluster (Fig. 3), while $L$. (V.) lainsoni and $L$. (V.) lindenbergi are the most divergent species. Finally, L. (V.) naiffi strains M5210, M5533 and E0337 are in the same cluster, despite the distinct Hae III PCR-F RFLPs of the EO337 strain (Fig. 2B). Our study also indicated that $L$. (V.) utingensis is closely related to the $L$. (V.) naiffi cluster as described (Fig. 3 ).

\section{Discussion}

The use of PCR-RFLPs for molecular diagnosis has been described in recent years as a valuable tool for typing Leishmania species. By employing the $h s p 70$ gene PCR-F-RFLP method described by Montalvo et al. (2012), we made three observations of new restriction pattern profiles that should be considered, especially when typing Brazilian strains. First, using PCR-F followed by Hae III digestion, we found two alleles of the $h s p 70$ gene in the $L$. (L.) amazonensis M2269 reference strain, which has been widely used in several studies.

The $h s p 70$ genes are highly conserved multicopy sequences located in tandem in Leishmania chromosome 28. Most of the polymorphisms found in $h s p 70$ genes are located in the intergenic regions (Ramirez et al., 2011). Interestingly, the allelic variation described here in $L$. (L.) amazonensis M2269 reference strain, present inside the coding region, was also found in some other isolates from Brazilian patients. These clinical isolates originated from different States in Brazil and were obtained from patients with different clinical manifestations (Coelho et al., 2014; de Oliveira et al., 2007).

A possible explanation for the presence of two sequences would be the presence of hybrids in natural populations of $L$. (L.) amazonensis, as already described in parasites of the L. (Viannia) subgenus (Dujardin et al., 1995; Nolder et al., 2007). The possibility of a mixed population or a hybrid cannot be discarded since parasites were not cloned before DNA isolation. The presence of these alleles could also be a result of hybridization between isolates, which could also not be discarded. However, sequencing and PCR-F-RFLP results do not indicate inter-species hybridization, since $99.9 \%$ sequence identity was found between both hsp70 alleles of the M2269 reference strain (Fig. 3 and data not shown).

This is, to the best of our knowledge, the first report of the presence of two alleles detected by the PCR-F-RFLP approach for the $h s p 70$ gene in $L$. (L.) amazonensis, a phenomenon that could be explained by the genetic diversity of Brazilian clinical isolates of this species (de Oliveira et al., 2007; Valdivia et al., 2017). Considering that parasites in the L. (Viannia) subgenus present higher genetic diversity than $L$. (L.) amazonensis (Cupolillo et al., 2003; da Silva et al., 2010; Montalvo et al., 2012), it is quite possible that different allelic patterns will be found when a greater number of isolates of each $L$. (Viannia) species are examined.

Testing this PCR-RFLP strategy as a routine approach for Leishmania species identification in our lab, we employed a panel of $L$. (Viannia) species. This led to the observation of a second instance, in $L$. (V.) naiffi strains, where PCR-F-RFLP with Hae III also revealed intra-species polymorphisms. The strain EO337 presented a different profile when compared to the two other strains of $L$. (V.) naiffi or the other L. (Viannia) species analyzed in this study. Three other enzymes used in silico as well as the phylogenetic analysis grouped these strains of
L. (V.) naiffi in the same profile, ruling out the possibility of species misidentification. The different geographic origin of these strains might explain these observations.

Despite the fact that the PCR-F-RFLP with Hae III is not straightforward for the discrimination of $L$. (V.) braziliensis/L. (V.) peruviana and L. (V.) naiffi (Montalvo et al., 2012) (Fig. 2B) and also L. (V.) utingensis (Table 2), this restriction enzyme is a useful alternative to discriminate $L$. (V.) guyanensis and $L$. (V.) braziliensis, which together with $L$. (L.) amazonensis are the main causative species of leishmaniasis in Brazil. As an alternative, in silico analysis revealed that Sdu I and Mbo I could be used to discriminate $L$. (V.) braziliensis/L. (V.) peruviana and $L$. (V.) naiffi but not $L$. (V.) utingensis (Table 2 ).

Leishmania $(V$.$) lindenbergi must also be considered when Brazilian$ clinical isolates are typed, especially in Amazon region, where it was already reported in patients with cutaneous leishmaniasis (Silveira et al., 2002). Similarly, Hae III was not useful to discriminate $L$. (V.) lindenbergi and $L$. (V.) guyanensis/L. (V.) panamensis. An alternative to this approach could be the use of Eco RII to discriminate $L$. $(V$.) lindenbergi from other L. (Viannia) species.

The third point raised during our analyses was that it was sometimes difficult to distinguish $L(V$.) shawi's digestion profile with Hae III (Fig. 2 and Table 2) from those generated by $L$. (V.) braziliensis and $L$. (V.) naiffi. The $120 \mathrm{pb}$ fragment present in $L(V$.) shawi could be difficult to separate from the $134 \mathrm{pb}$ bands observed in $L$. (V.) braziliensis and $L$. (V.) naiffi, in the absence of a good electrophoresis analysis. In this case, polyacrylamide or high-resolution agarose gels must be used to discriminate these small fragments.

In conclusion, using the PCR-F-RFLP protocol with Hae III for species identification, we detected intra-species variation in some Brazilian clinical isolates of $L$. (L.) amazonensis and in L. (Viannia) species. These polymorphisms must be taken in consideration when identifying strains of $L$. (V.) braziliensis and $L$. (V.) naiffi as $L(V$.) shawi. Our findings indicate that restriction polymorphic sites may result in parasite mistyping and that as more strains of a species are examined more polymorphic sites will be detected. On the other hand, nucleotide sequence of the 1,286 bp hsp70 amplified product completely ruled out the possibility of misidentification of all species and strains of Leishmania endemic in Brazil.

\section{Acknowledgments}

We are grateful to Carmen S. A. Takata for performing the sequencing. The authors also thank Jenicer K. U. Yokoyama-Yasunaka for technical assistance.

\section{Funding}

This work was supported by research grants from Fundação de Amparo à Pesquisa do Estado de São Paulo (FAPESP, 2011/20484-7 and 2015/09080-2) and Conselho Nacional de Desenvolvimento Científico e Tecnológico (CNPq, 473343/2012-6), Brazil. SRBU is the recipient of a senior researcher scholarship from CNPq. ACC and CRE were fellows supported by FAPESP (2012/14629-5 and 2016/23405-4).

\section{References}

Alvar J, Velez ID, Bern C, Herrero M, Desjeux P, Cano J, et al. Leishmaniasis worldwide and global estimates of its incidence. PLoS One 2012;7(5), e35671.

Arevalo J, Ramirez L, Adaui V, Zimic M, Tulliano G, Miranda-Verastegui C, et al. Influence of Leishmania (Viannia) species on the response to antimonial treatment in patients with American tegumentary leishmaniasis. J Infect Dis 2007;195(12):1846-51.

Asato Y, Oshiro M, Myint CK, Yamamoto Y, Kato H, Marco JD, et al. Phylogenic analysis of the genus Leishmania by cytochrome b gene sequencing. Exp Parasitol 2009;121(4): 352-61.

Boite MC, Mauricio IL, Miles MA, Cupolillo E. New insights on taxonomy, phylogeny and population genetics of Leishmania (Viannia) parasites based on multilocus sequence analysis. PLoS Negl Trop Dis 2012;6(11), e1888. 
Braga RR, Lainson R, Ishikawa EA, Shaw JJ. Leishmania (Viannia) utingensis n. sp., a parasite from the sandfly Lutzomyia (Viannamyia) tuberculata in Amazonian Brazil. Parasite 2003;10(2):111-8.

Chance ML, Peters W, Shchory L. Biochemical taxonomy of Leishmania. I. Observations on DNA. Ann Trop Med Parasitol 1974;68(3):307-16

Coelho AC, Trinconi CT, Costa CH, Uliana SR. In vitro and in vivo miltefosine susceptibility of a Leishmania amazonensis isolate from a patient with diffuse cutaneous leishmaniasis. PLoS Negl Trop Dis 2014;8(7), e2999.

Cupolillo E, Grimaldi Jr G, Momen H. A general classification of New World Leishmania using numerical zymotaxonomy. Am J Trop Med Hyg 1994;50(3):296-311.

Cupolillo E, Grimaldi Junior G, Momen H, Beverley SM. Intergenic region typing (IRT): a rapid molecular approach to the characterization and evolution of Leishmania. Mol Biochem Parasitol 1995;73(1-2):145-55.

Cupolillo E, Brahim LR, Toaldo CB, De Oliveira-Neto MP, De Brito ME, Falqueto A, et al. Genetic Polymorphism and Molecular Epidemiology of Leishmania (Viannia) braziliensis from Different Hosts and Geographic Areas in Brazil. J Clin Microbiol 2003;41(7):3126-32.

da Silva LA, de Sousa Cdos S, da Graca GC, Porrozzi R, Cupolillo E. Sequence analysis and PCR-RFLP profiling of the $h s p 70$ gene as a valuable tool for identifying Leishmania species associated with human leishmaniasis in Brazil. Infect Genet Evol 2010;10(1):77-83.

de Oliveira JP, Fernandes F, Cruz AK, Trombela V, Monteiro E, Camargo AA, et al. Genetic diversity of Leishmania amazonensis strains isolated in northeastern Brazil as revealed by DNA sequencing. PCR-based analyses and molecular karyotyping. Kinetoplastid Biol Dis 2007;6:5

Dujardin JC, Banuls AL, Llanos-Cuentas A, Alvarez E, DeDoncker S, Jacquet D, et al. Putative Leishmania hybrids in the Eastern Andean valley of Huanuco. Peru. Acta Trop 1995; 59(4):293-307.

Espinosa OA, Serrano MG, Camargo EP, Teixeira MM, Shaw JJ. An appraisal of the taxonomy and nomenclature of trypanosomatids presently classified as Leishmania and Endotrypanum. Parasitology 2016:1-13.

Folgueira C, Canavate C, Chicharro C, Requena JM. Genomic organization and expression of the HSP70 locus in New and Old World Leishmania species. Parasitology 2007; 134(Pt 3):369-77.

Fraga J, Montalvo AM, De Doncker S, Dujardin JC, Van der Auwera G. Phylogeny of Leishmania species based on the heat-shock protein 70 gene. Infect Genet Evol 2010; 10(2):238-45.

Fraga J, Veland N, Montalvo AM, Praet N, Boggild AK, Valencia BM, et al. Accurate and rapid species typing from cutaneous and mucocutaneous leishmaniasis lesions of the New World. Diagn Microbiol Infect Dis 2012;74(2):142-50.

Fraga J, Montalvo AM, Maes L, Dujardin JC, Van der Auwera G. HindII and SduI digests of heat-shock protein 70 PCR for Leishmania typing. Diagn Microbiol Infect Dis 2013;77 (3):245-7.

Garcia L, Kindt A, Bermudez H, Llanos-Cuentas A, De Doncker S, Arevalo J, et al. Cultureindependent species typing of neotropical Leishmania for clinical validation of a PCR-based assay targeting heat shock protein 70 genes. J Clin Microbiol 2004;42(5): 2294-7.

Lainson R, Shaw JJ. Leishmania (Viannia) naiffi sp. n., a parasite of the armadillo, Dasypus novemcinctus (L.) in Amazonian Brazil. Ann Parasitol Hum Comp 1989;64(1):3-9.

Lainson R, Shaw JJ, Ward RD, Ready PD, Naiff RD. Leishmaniasis in Brazil: XIII. Isolation of Leishmania from armadillos (Dasypus novemcinctus), and observations on the epide- miology of cutaneous leishmaniasis in north Para State. Trans R Soc Trop Med Hyg 1979;73(2):239-42.

Laison R, Shaw JJ, Ward RD, Fraiha H. Leishmaniasis in Brazil. IX. Considerations on the Leishmania braziliensis complex. Importance of sandflies of the genus Psychodopygus (Mangabeira) in the transmission of L. braziliensis braziliensis in north Brazil. Trans R Soc Trop Med Hyg 1973;67(2):184-96.

Marfurt J, Nasereddin A, Niederwieser I, Jaffe CL, Beck HP, Felger I. Identification and differentiation of leishmania species in clinical samples by PCR amplification of the miniexon sequence and subsequent restriction fragment length polymorphism analysis. J Clin Microbiol 2003;41(7):3147-53.

Miles MA, Povoa MM, de Souza AA, Lainson R, Shaw JJ. Some methods for the enzymic characterization of Latin-American Leishmania with particular reference to Leishmania mexicana amazonensis and subspecies of Leishmania hertigi. Trans R Soc Trop Med Hyg 1980;74(2):243-52.

Montalvo AM, Fraga J, Maes I, Dujardin JC, Van der Auwera G. Three new sensitive and specific heat-shock protein 70 PCRs for global Leishmania species identification. Eur J Clin Microbiol Infect Dis 2012;31(7):1453-61.

Murray HW, Berman JD, Davies CR, Saravia NG. Advances in leishmaniasis. Lancet 2005 366(9496):1561-77.

Nicholas KB, Nicholas Jr HB, Deerfield DW. GeneDoc: analysis and visualization of genetic variation. Embnew News 1997;4:14.

Nolder D, Roncal N, Davies CR, Llanos-Cuentas A, Miles MA. Multiple hybrid genotypes of Leishmania (viannia) in a focus of mucocutaneous Leishmaniasis. Am J Trop Med Hyg 2007;76(3):573-8.

Ramirez CA, Requena JM, Puerta CJ. Identification of the HSP70-II gene in Leishmania braziliensis HSP70 locus: genomic organization and UTRs characterization. Parasit Vectors 2011;4:166.

Rioux JA, Lanotte G, Serres E, Pratlong F, Bastien P, Perieres J. Taxonomy of Leishmania. Use of isoenzymes. Suggestions for a new classification. Ann Parasitol Hum Comp 1990; 65(3):111-25.

Schonian G, Nasereddin A, Dinse N, Schweynoch C, Schallig HD, Presber W, et al. PCR diagnosis and characterization of Leishmania in local and imported clinical samples. Diagn Microbiol Infect Dis 2003;47(1):349-58.

Silveira FT, Shaw JJ, Braga RR, Ishikawa E. Dermal leishmaniasis in the Amazon region of Brazil: Leishmania (Viannaia) lainsoni sp.n., a new parasite from the State of Para. Mem Inst Oswaldo Cruz 1987;82(2):289-91.

Silveira FT, Ishikawa EA, De Souza AA, Lainson R. An outbreak of cutaneous leishmaniasis among soldiers in Belem, Para State, Brazil, caused by Leishmania (Viannia) lindenbergi n. sp. A new leishmanial parasite of man in the Amazon region. Parasite 2002;9(1):43-50.

Stamatakis A. RAxML-VI-HPC: maximum likelihood-based phylogenetic analyses with thousands of taxa and mixed models. Bioinformatics 2006;22(21):2688-90.

Swofford DL. PAUP*: Phylogenetic Analysis Using Parsimony (*and Other Methods). Sunderland, Massachusetts: Sinauer Associates; 2002.

Valdivia HO, Almeida LV, Roatt BM, Reis-Cunha JL, Pereira AA, Gontijo C, et al. Comparative genomics of canine-isolated Leishmania (Leishmania) amazonensis from an endemic focus of visceral leishmaniasis in Governador Valadares, southeastern Brazil. Sci Rep 2017;7:40804

Van der Auwera G, Dujardin JC. Species typing in dermal leishmaniasis. Clin Microbiol Rev 2015;28(2):265-94. 